\title{
Improved Salinity Tolerance in Carrizo Citrange Rootstock through Overexpression of Glyoxalase System Genes
}

\author{
Ximena Alvarez-Gerding, ${ }^{1,2}$ Rowena Cortés-Bullemore, ${ }^{1}$ \\ Consuelo Medina, ${ }^{1}$ Jesús L. Romero-Romero, ${ }^{1,2,3}$ Claudio Inostroza-Blancheteau, ${ }^{4}$ \\ Felipe Aquea, ${ }^{1,5,6}$ and Patricio Arce-Johnson ${ }^{1}$

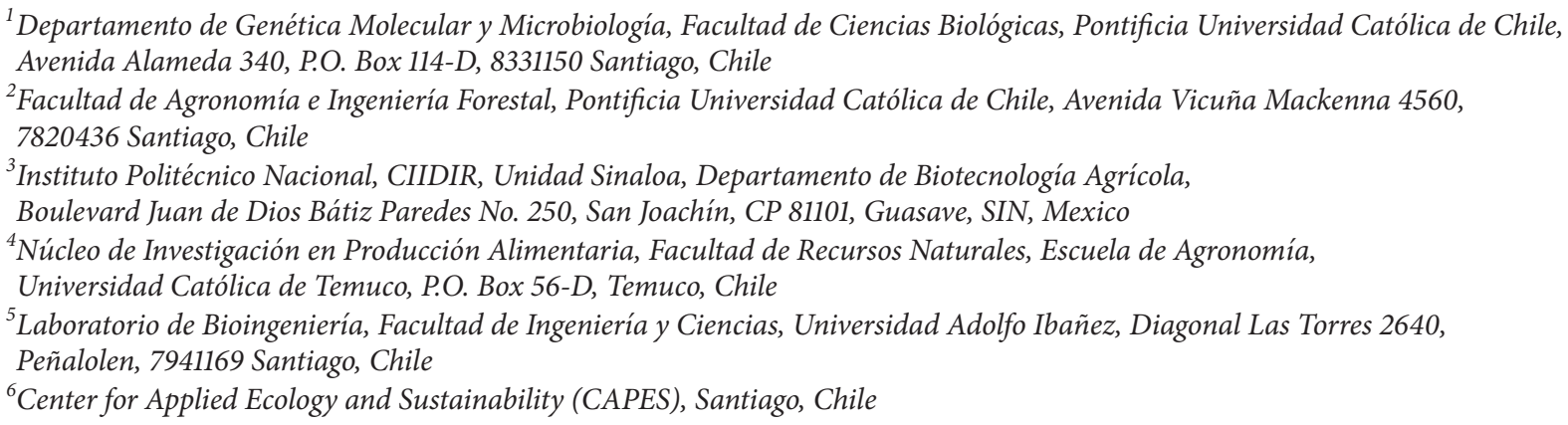

Correspondence should be addressed to Patricio Arce-Johnson; parce@bio.puc.cl

Received 27 February 2015; Revised 30 May 2015; Accepted 21 June 2015

Academic Editor: Sudhir Sopory

Copyright (c) 2015 Ximena Alvarez-Gerding et al. This is an open access article distributed under the Creative Commons Attribution License, which permits unrestricted use, distribution, and reproduction in any medium, provided the original work is properly cited.

\begin{abstract}
Citrus plants are widely cultivated around the world and, however, are one of the most salt stress sensitive crops. To improve salinity tolerance, transgenic Carrizo citrange rootstocks that overexpress glyoxalase I and glyoxalase II genes were obtained and their salt stress tolerance was evaluated. Molecular analysis showed high expression for both glyoxalase genes (BjGlyI and PgGlyII) in 5H03 and 5H04 lines. Under control conditions, transgenic and wild type plants presented normal morphology. In salinity treatments, the transgenic plants showed less yellowing, marginal burn in lower leaves and showed less than $40 \%$ of leaf damage compared with wild type plants. The transgenic plants showed a significant increase in the dry weight of shoot but there are no differences in the root and complete plant dry weight. In addition, a higher accumulation of chlorine is observed in the roots in transgenic line $5 \mathrm{H} 03$ but in shoot it was lower. Also, the wild type plant accumulated around $20 \%$ more chlorine in the shoot compared to roots. These results suggest that heterologous expression of glyoxalase system genes could enhance salt stress tolerance in Carrizo citrange rootstock and could be a good biotechnological approach to improve the abiotic stress tolerance in woody plant species.
\end{abstract}

\section{Introduction}

Citrus are perennial plants that produce fruit with a highvalue worldwide and are cultivated in tropical, subtropical, and Mediterranean climates. Drought and salinity are becoming particularly widespread in many regions and may cause serious salinization of more than $50 \%$ of all arable lands by the year 2050 [1]. High salinity can cause severe damage to plants leading to considerable reduction in their productivity.
Lemons and oranges are the most salinity sensitive of all agricultural crops [2].

Salinity is mainly constituted by sodium chloride $(\mathrm{NaCl})$ and high levels of salt exert its negative impact, mainly by disrupting the ionic and osmotic equilibrium of the cell, leading the plant growth inhibition and even death [3].

The ability of citrus trees to tolerate salinity varies among different species and depends on the rootstock. Carrizo citrange (Citrus sinensis L. Osb. x Poncirus trifoliata L. 
Raf.) is the most popular rootstock worldwide, because of its tolerance to diseases and flooding, moderate cold tolerance, good fruit quality, high yield, and good compatibility with varieties [4]. However, a major drawback is its sensitivity to salinity, which restricts its productive use [5]. A few citrus rootstock-breeding programs have succeeded in increasing salinity tolerance. In this context, genetic modification arises as an alternative to conventional breeding. Successful protocols for genetic transformation of Carrizo citrange have been developed over the past years [6]. To improve salinity tolerance, many alternatives have been described in annual species through gene transfer [7]. Among them, the overexpression of the glyoxalase system (glyoxalases I and II) has been demonstrated to be a good approach to enhance salinity tolerance in different plants like tobacco [8] and tomato [9]. This defense mechanism has been described which naturally exists in different plants. For example, the activity of glyoxalase I (Gly I) was increased in salt stress conditions in tolerant rice variety [10]. In addition, plants under high temperature induced an oxidative stress by simultaneously increasing nonenzymatic and enzymatic antioxidant responses, as well as detoxification systems for methylglyoxal (MG) [11].

In this work, we evaluate the response to salinity conditions of transgenic Carrizo citrange that overexpress two genes coding for the glyoxalase system (BjGlyI and PgGlyII) from Brassica juncea and Pennisetum glaucum, respectively.

\section{Materials and Methods}

2.1. Plant Material. Carrizo citrange seeds were soaked in a fungicide solution of Captan $1 \%(1 \mathrm{~g} / \mathrm{L})$ plus Benlate $(0.8 \mathrm{~g} / \mathrm{L})$ in a shaker at $30^{\circ} \mathrm{C}$ for $48 \mathrm{~h}$. Seeds were germinated in medium Murashige and Tucker solidified with $0.7 \%$ agar (w/v). To prevent contamination, $3 \mathrm{~mL} / \mathrm{L}$ Plant Preservative Mixture (PPM, Plant Cell Technology) was added without sucrose. Seeds were then sown and placed in a germination chamber in darkness at $28 \pm 2^{\circ} \mathrm{C}$.

2.2. Genetic Constructions. The double construct containing BjGlyI from Brassica juncea (GenBank accession number Y13239) and PgGlyII from Pennisetum glaucum (GenBank accession number AF508863.1) was driven by independent CaMV 35S promoters in the vector pCAMBIA1304 (Figure 1(a)).

\subsection{Carrizo Citrange Transformation and Plant Regenera-} tion. Epicotyl segments were transformed as described by Cervera et al. [6] using the Agrobacterium tumefaciens strain EHA105. Epicotyls were subsequently transferred to Petri plates containing hygromycin $(3.5 \mathrm{mg} / \mathrm{L})$ for selection. After three weeks in darkness, plates were transferred to a photoperiod of $16 \mathrm{~h}$ light and subcultured every two weeks in the same medium. Rooted explants were acclimated in hermetic transparent pots containing $50 \%$ perlite and $50 \%$ peat moss in a greenhouse and vegetatively propagated. Subsequently, after 12 weeks, plants were transferred to individual pots filled with sterile sand for salinity tolerance experiments.

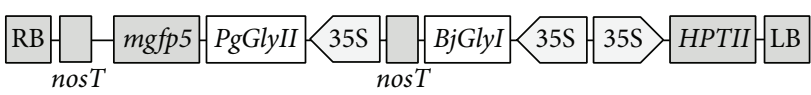

(a)
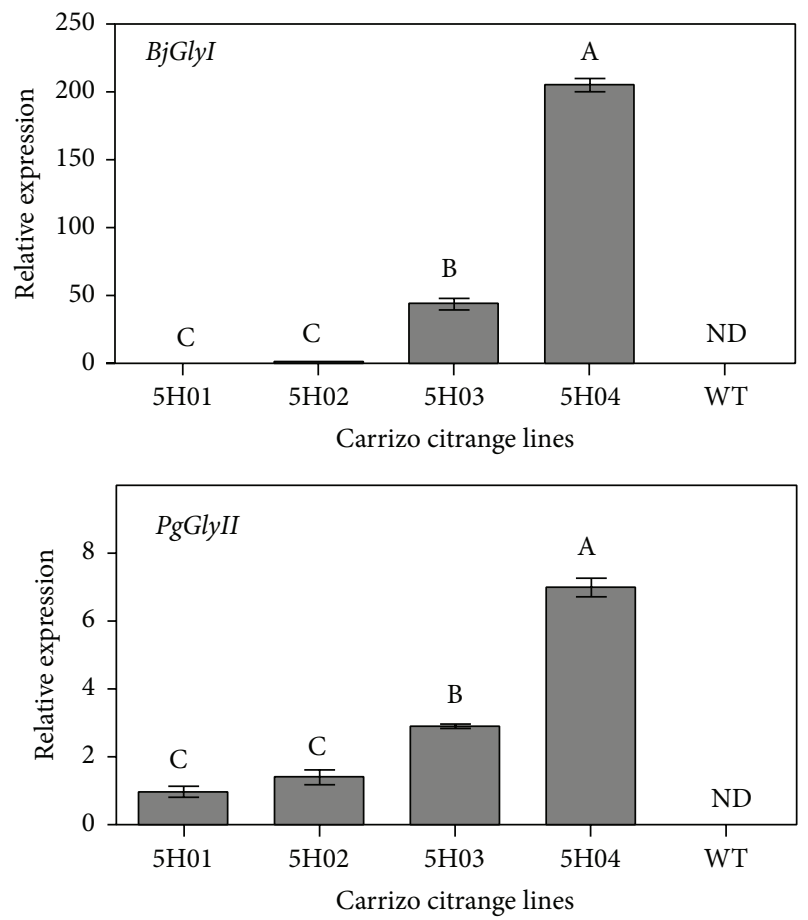

(b)

FIGURE 1: (a) Schematic representation of the T-DNA regions of the transformation vectors. BjGlyI + PgGlyII construction containing glyoxalase I from Brassica juncea (GlyI) and glyoxalase II from Pennisetum glaucum (GlyII) driven by independent CaMV35S promoters and containing the HPTII selectable marker gene. (b) $B j G l y I+P g G l y I I$ expression in Carrizo citrange transgenic lines. The transcript abundance was normalized to the lowest expression for each gene. Bars represent means of three plants \pm standard error. Different uppercase letters within each figure and gene indicate significant differences at $P \leq 0.05$. ND: not detected.

2.4. Transgene Evaluation. Genomic DNA was isolated from leaf tissue using the Plant Genomic DNA extraction minikit (Favorgen Biotech Corp.). PCR amplifications of integrated transgenes in BjGlyI + PgGlyII lines were performed using primers BjGlyI-Fwd 5'-ATGGCGTCGGAAGCGAA-3' and BjGlyI-Rev $5^{\prime}$-CGATCCAGTAGCCATCAG-3' for glyoxalase I and PgGlyII-Fwd $5^{\prime}$-TTAAAAGTTATCCTTCGCTCG-3' and PgGlyII-Rev $5^{\prime}$-ATGCGGATGCTGTCCAAGGCG-3' for glyoxalase II, respectively. In addition, PCR genotyping was made using the primers $5^{\prime}$-TCGTCCATCACAGTTTGCC- $3^{\prime}$ and $5^{\prime}$-AAAAGCCTGAACTCACCGC- $3^{\prime}$ for hygromycin phosphotransferase protein (HPTII). The genotyping was performed initially in plants grown in vitro and then was repeated in the same plants grown in greenhouse conditions (2-month-old).

2.5. Quantitative Gene Expression. The RNA extraction, cDNA synthesis, and quantification of gene expression were 
performed as described previously [12]. Primers qBjGlyI-Fwd $5^{\prime}$-TGGGCATATTGGGGTTACAG-3' and qBjGlyI-Rev $5^{\prime}$ CCATCGTGTGGTTTCTTGAC-3'; and qPgGlyII-Fwd $5^{\prime}$ ACGCTGCTCGTCATGCCTCT- $3^{\prime}$ and qPgGlyII-Rev $5^{\prime}$ ATTTGCAGCGACGACGAGAC- $3^{\prime}$ were used to analyze the expression of BjGlyI and GlyII, respectively. Primers were evaluated with conventional PCR to discard any endogenous amplification glyoxalase genes in wild type (WT) Carrizo citrange plants. Stratagene model Mx3000P and the SensimixTM SYBR-Green kit were used for qRT-PCR analysis and data was normalized using Elongation Factor 1 [13].

2.6. Evaluation of Salinity Tolerance in Carrizo Citrange Plants. To evaluate salinity tolerance, Carrizo citrange transgenic and wild type plants were irrigated twice a week with Hoagland solution diluted to $25 \% \mathrm{v} / \mathrm{v}$ (control treatment) or Hoagland solution diluted to $25 \% \mathrm{v} / \mathrm{v}$ supplemented with $75 \mathrm{mM} \mathrm{NaCl}$ (saline treatment). After 30 days, plants were divided into shoots and roots and dried at $80^{\circ} \mathrm{C}$ for $72 \mathrm{~h}$ to measure dry weight (DW) and the $\mathrm{Na}^{+}$and $\mathrm{Cl}^{-}$concentration, which was conducted by the laboratories AgroLab Ltda., Santiago, Chile.

2.7. Statistical Analyses. Statistical analyses were performed with InfoStat software (http://www.infostat.com.ar). Experiments were carried out using a completely randomized design. Analysis of variance and covariance was applied depending on the trait. Tukey's $(P \leq 0.05)$ multiple comparison procedure was used when significant differences were found.

\section{Results}

3.1. Integration and Expression of Glyoxalase System Genes in Carrizo Citrange Transgenic Lines. Several transformation experiments to overexpress the glyoxalase system were carried out using epicotyls as explants. After a twelveweek period, hygromycin-resistant shoots were tested for transgene integration and expression by PCR and qRT-PCR analysis, respectively. The PCR genotyping was performed as described before in Materials and Methods (data not shown). Four transgenic lines that show transgene amplification and expressions of BjGlyI + PgGlyII (named 5H01, 5H02, 5H03, and 5H04) were chosen. The expression of transgenes was not detected in Carrizo citrange wild type plants (Figure 1(b)). For glyoxalase system transgenic lines, the highest expression for both BjGlyI and PgGlyII genes was observed in 5H03 and 5H04 in comparison with the transgenic lines 5H01 and 5H02 (Figure 1(b)). These genes are under the transcriptional control of $35 \mathrm{~S}$ promotor. However, the BjGlyI gene has another $35 \mathrm{~S}$ promoter upstream that control the expression of HPTII. The genetic architecture of the transgene can explain the huge difference in the level of expression of both transgenes inside the same line.

3.2. Tolerance of Transgenic Carrizo Citrange Plants to Moderate Salinity Levels. To assess salinity tolerance of the transgenic Carrizo citrange rootstock, plants were irrigated with saline solutions to compare their response in qualitative and quantitative parameters. Under control conditions, transgenic and wild type plants presented normal plant and leaf morphology (Figures 2(a), 2(c), and 2(e)). When the lines were subjected to salinity treatments, more than $80 \%$ of wild type leaves became wilted (Figures 2(a) and 2(b)). In contrast, $5 \mathrm{H} 03$ and 5H04 transgenic lines showed less than $40 \%$ of leaf damage in the saline treatments (Figures 2(c)-2(f)). BjGlyI + PgGlyII transgenic lines 5H03 and 5H04 showed less yellowing and marginal burn in lower leaves under saline treatment. The other two transgenic lines 5H01 and 5H02 showed an intermediate phenotype (data not shown).

With the purpose of quantifying how saline treatments affect growth, the dry weight (DW) of the shoot, root, and whole plant was measured. Significant differences in the DW were found in the tissues analyzed of the wild type plants (Figure 3). The DW of shoots, roots, and whole plants was decreased by $44 \%, 70 \%$, and $57 \%$, respectively, under saline treatment in wild type plants. The lines 5H03 and 5H04 showed no significant differences in the root and complete plant DW under saline treatment (Figure 3). However, there were significant differences in the shoot; lines $5 \mathrm{H} 03$ and $5 \mathrm{H} 04$ showed an increase in DW of $46 \%$ and $28 \%$, respectively.

3.3. Chloride and Sodium Accumulation in Roots and Shoot. Salt treatment increased the accumulation of $\mathrm{Cl}^{-}$and $\mathrm{Na}^{+}$ in roots and shoots in all lines (Figure 4). The accumulation of $\mathrm{Cl}^{-}$was higher in roots of $5 \mathrm{H} 03$ transgenic lines but in shoots accumulation was lower. Also, a significant higher $\mathrm{Na}^{+}$accumulation showed $5 \mathrm{H} 03$ transgenic line in this organ. No significant differences were observed between ions and organs in the 5H04 transgenic line. In addition, the WT line accumulated $\sim 20 \%$ more in the shoots than roots (Figure 4 ).

\section{Discussion}

Citrus plants are very sensitive to salinity, limiting their yield under this condition. Grafting onto salinity tolerance rootstocks is an alternative to overcome this problem. In this work, we report the transformation of Carrizo citrange rootstock with genes that codify for the glyoxalase system (BjGlyI and PgGlyII). For salinity tolerance assessment, plants were irrigated with $\mathrm{NaCl}$ under greenhouse conditions. The glyoxalase pathway might be operating through detoxification and cellular repair [8] leading to a better performance by decreasing oxidative stress, thus allowing higher dry mass accumulation as demonstrated by Singla-Pareek et al. [14] and Álvarez-Viveros et al. [9]. Specifically, the second enzyme of glyoxalase pathway (GlyII) that detoxifies cytotoxic metabolite methylglyoxal (MG) in salinity plant response contains a binuclear $\mathrm{Zn} / \mathrm{Fe}$ centre in its active site and chelation that are essential for its activity [15].

Here, we evaluated the effect of overexpressing BjGlyI and $P g G l y I I$ in transgenic plants on biomass and phenotype under salinity stress. The transgenic 5H03 and 5H04 lines showed higher expression levels of both genes (Figure 1(b)). Shoot, root, and whole plant DW accumulation was reduced in Carrizo citrange WT by saline conditions, but not in 5H03 and 


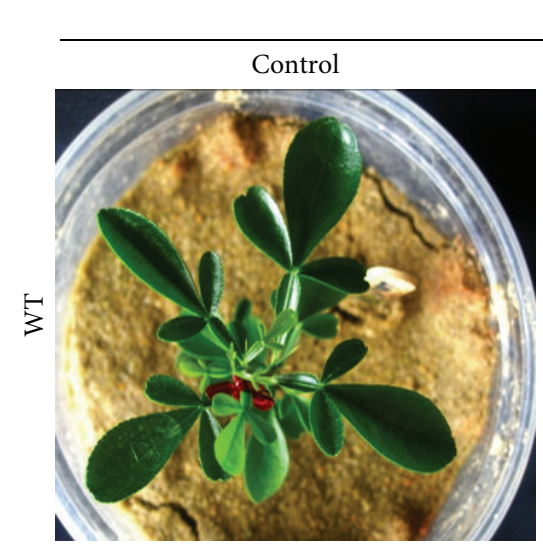

(a)

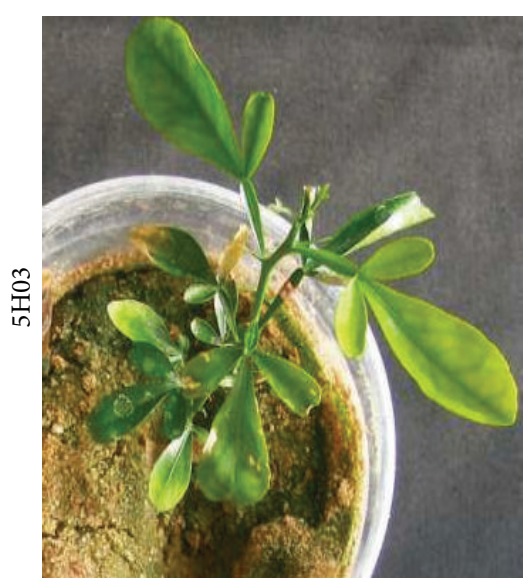

(c)

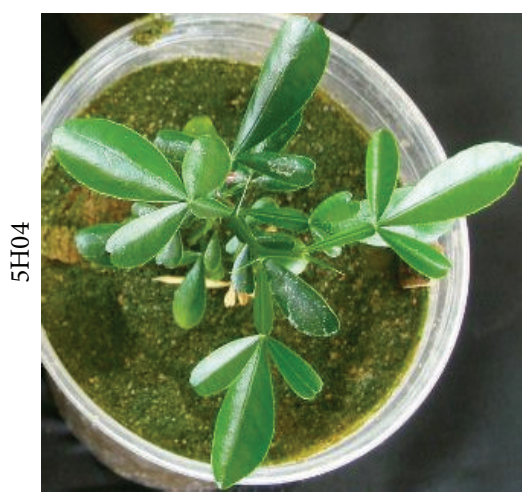

(e)

\section{Treatment}

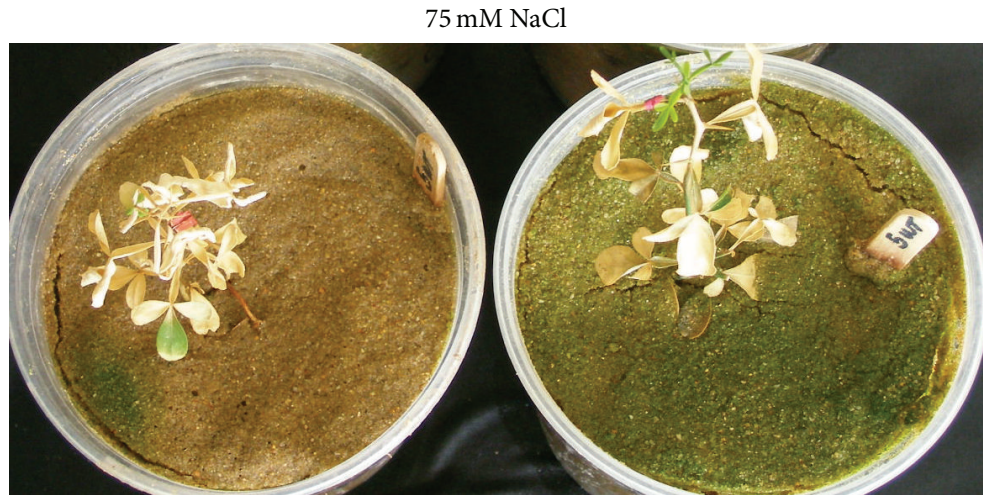

(b)
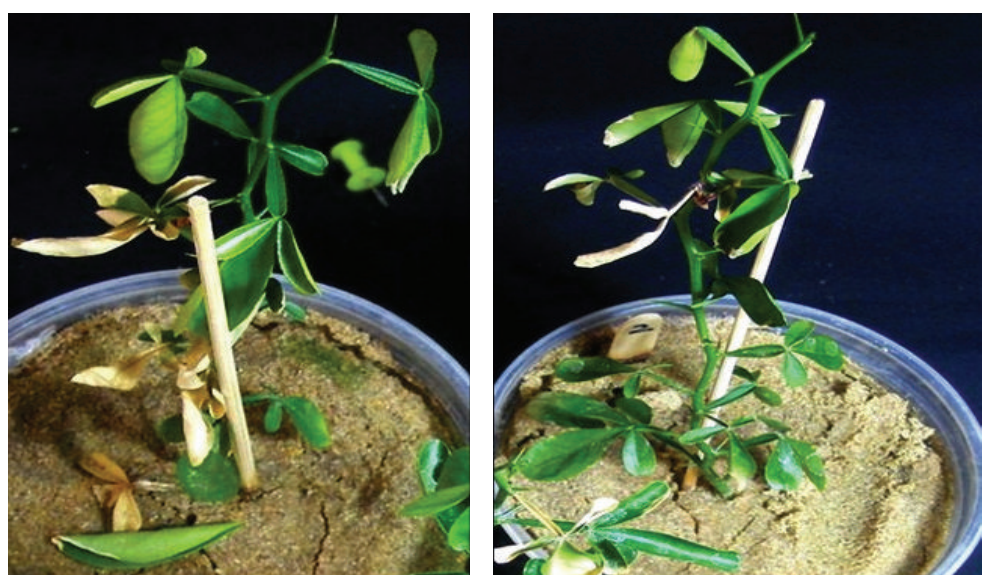

(d)
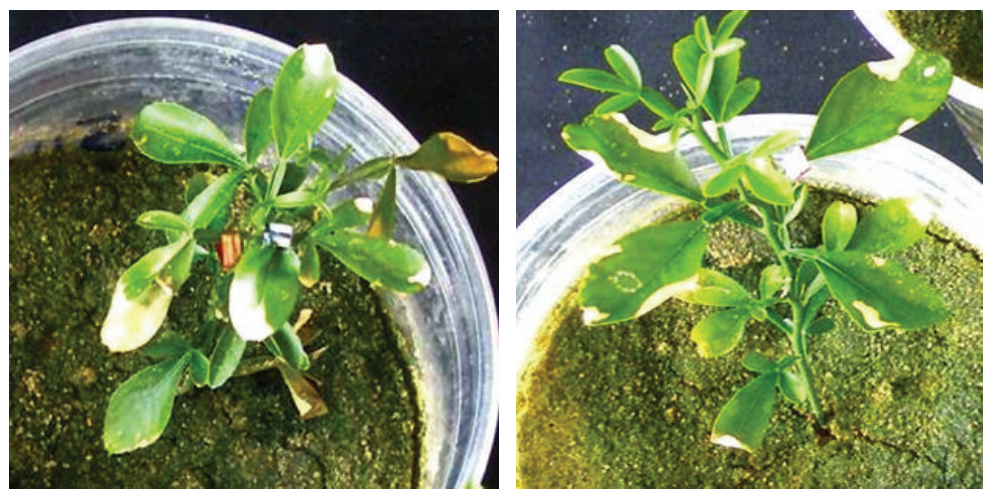

(f)

FIgURE 2: Citrus plant phenotypes after $30 \mathrm{~d}$ under $75 \mathrm{mM} \mathrm{NaCl}$ treatments. ((a), (c), and (e)) WT and transgenic plants under normal conditions. ((b), (d), and (f)) WT and transgenic plants under salinity stress treatment $(75 \mathrm{mM} \mathrm{NaCl})$.

5H04 transgenic lines (Figure 3), which exhibited a healthy leaf phenotype (Figures 2(c)-2(f)). However, the shoot-toroot DW ratio under control conditions of BjGlyI + PgGlyII 5H03 line was similar to WT plants, indicating that both root and shoot kept growing (Figure 3). In BjGlyI + PgGlyII 5H03 and 5H04 lines, root DWs were most affected by saline treatment. This may be associated with the vulnerability of the root to salinity as an indicator of salt accumulations in this zone [16]. In general, this is associated with the greater accumulation of $\mathrm{Cl}^{-}$in roots (Figure 4), in line $5 \mathrm{H03}$, and it is correlated with lower $\mathrm{Cl}^{-}$accumulation and increased $\mathrm{Na}^{+}$is observed in leaves of the $5 \mathrm{H} 03$ lines. Nonetheless, no significant differences were found between the ions in roots and leaves of the 5H04 line showing similar accumulation in both organs (Figure 4). However, the responses of 5H03 have been observed in other rootstocks, where plant growth 

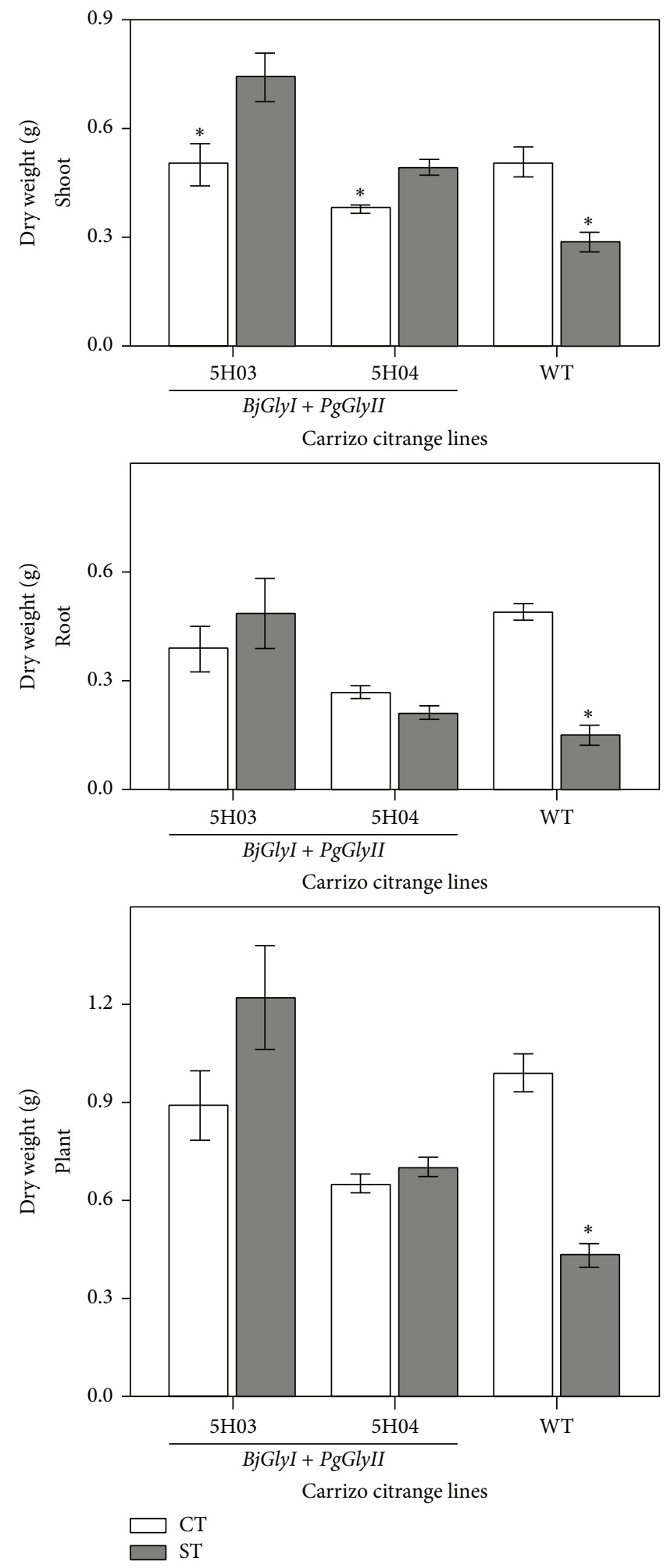

FIGURE 3: Dry weight of whole plants, shoots, and roots of WT and transgenic plants after a five-week salinity treatment. CT (control) and ST (salinity stress) treatments were compared by Student's $t$-test within each line. 

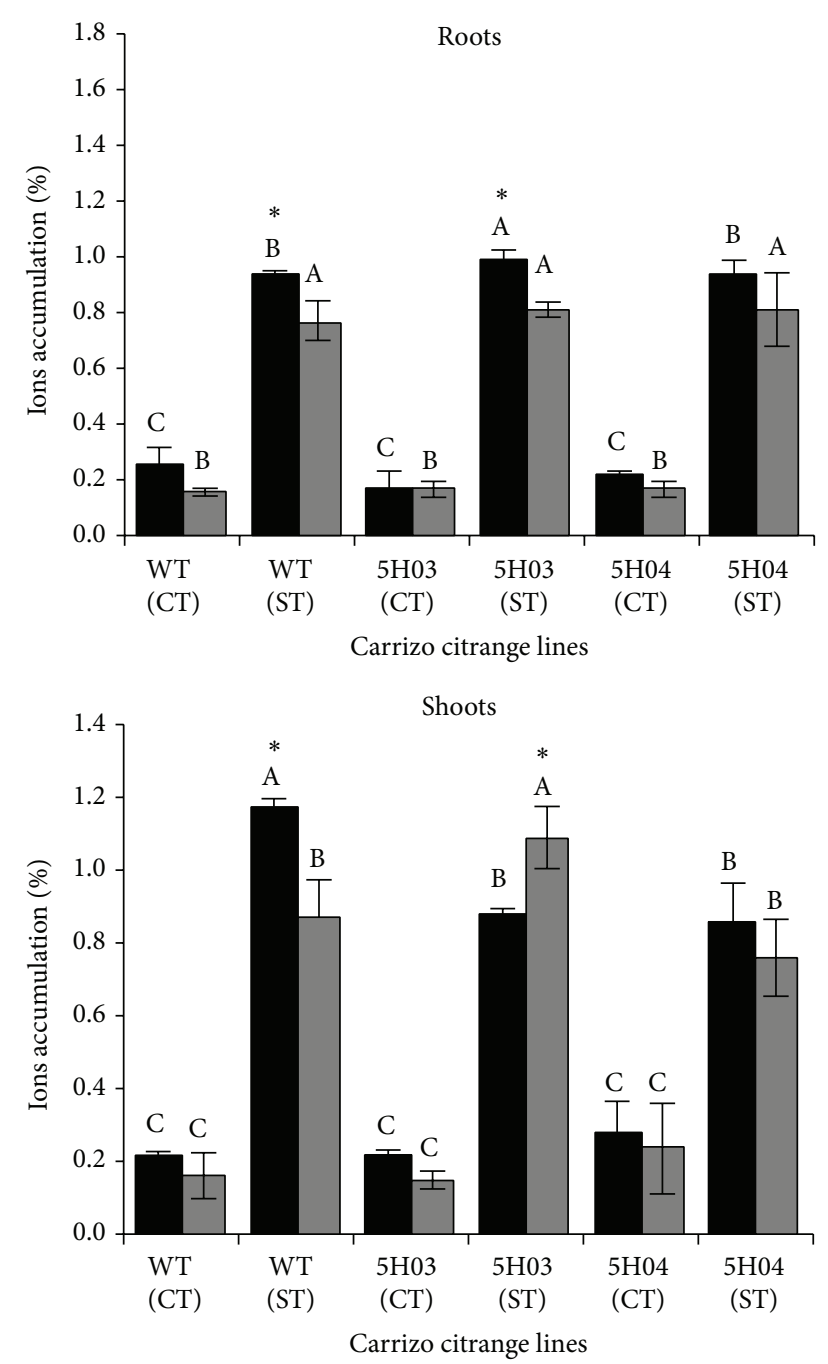

$\mathrm{Cl}^{-}$
$\square \mathrm{Na}^{+}$

FIGURE 4: Effects of salt stress on the accumulation of chloride $\left(\mathrm{Cl}^{-}\right)$ and sodium $\left(\mathrm{Na}^{+}\right)$in roots and shoots of Carrizo citrange rootstock under fresh water (control) and salinity $(75 \mathrm{mM} \mathrm{NaCl})$. The values represent averages of three replicates \pm S.D. Different uppercase letters indicate significant differences $(P \leq 0.05)$ between lines in the same treatment. Asterisks indicate differences $(P \leq 0.05)$ between the treatments in the same line.

is related not only to the osmotic effect, but also to a gradual accumulation of toxic levels of $\mathrm{Cl}^{-}$and $\mathrm{Na}^{+}$in the leaves [17]. In this case, the overexpression of BjGlyI + PgGlyII correlated positively with biomass and phenotype, suggesting that the double transgene glyoxalase system is more effective when coping with salinity stress in Carrizo citrange plants. In other plant systems, like Pennisetum glaucum, it has been showed that GlyII transcript levels are elevated during several abiotic stresses including anoxia, hypoxia, drought, light, and salt. In earlier studies, exposure of the plants to salt stress had led to increase in GlyII transcript levels of 15-fold increases at $24 \mathrm{~h}$ after treatment [18], which confirms that GlyII is induced during abiotic stress and suggests that it may have a biological role in stress tolerance [19]. The results of this work are according to these papers.

\section{Conclusion}

In this work, we report the overexpression of the glyoxalase system in citrus plants. This study provides direct evidence that constitutive overexpression of the BjGlyI + PgGlyII genes improve salinity tolerance of Carrizo citrus rootstock under greenhouse conditions. This work could provide insights into the benefits of transgenesis in woody plant species increasing salinity tolerance. However, further experiments are necessary under both greenhouse and field conditions that complement and lead to a better analysis of how the overexpression of these genes is acting to change rootstock and/or variety performance.

\section{Conflict of Interests}

The authors declare that there is no conflict of interests regarding the publication of this paper.

\section{Acknowledgments}

The authors thank Dr. Sudhir K. Sopory, Plant Molecular Biology, International Center for Genetics Engineering and Biotechnology (ICGEB, New Delhi, India) for kindly providing the BjGlyI + PgGlyII DNA construction and Sandy Rojas for technical assistance. This research was supported by funds from InnovaChile-CORFO, Project Codes 204-4037 and NC 130030 "Millennium Nucleus Center for Plant Systems and Synthetic Biology.” Ximena Alvarez-Gerding was supported by a VRI-PUC PhD fellowship. Felipe Aquea was supported by CAPES FB-002-2014, CONICYT.

\section{References}

[1] W. Wang, B. Vinocur, and A. Altman, "Plant responses to drought, salinity and extreme temperatures: towards genetic engineering for stress tolerance," Planta, vol. 218, no. 1, pp. 1-14, 2003.

[2] E. V. Maas, "Salinity and citriculture," Tree Physiology, vol. 12, no. 2, pp. 195-216, 1993.

[3] N. Tuteja, "Mechanisms of high salinity tolerance in plants," Methods in Enzymology, vol. 428, pp. 419-438, 2007.

[4] R. M. Pérez-Clemente, A. Montoliu, S. I. Zandalinas, C. de Ollas, and A. Gómez-Cadenas, "Carrizo citrange plants do not require the presence of roots to modulate the response to osmotic stress," The Scientific World Journal, vol. 2012, Article ID 795396, 13 pages, 2012.

[5] V. Arbona, V. Flors, J. Jacas, P. García-Agustín, and A. GómezCadenas, "Enzymatic and non-enzymatic antioxidant responses of Carrizo citrange, a salt-sensitive citrus rootstock, to different levels of salinity," Plant and Cell Physiology, vol. 44, no. 4, pp. 388-394, 2003.

[6] M. Cervera, J. A. Pina, J. Juárez, L. Navarro, and L. Peña, "Agrobacterium-mediated transformation of citrange: factors affecting transformation and regeneration," Plant Cell Reports, vol. 18, no. 3-4, pp. 271-278, 1998. 
[7] M. P. Apse and E. Blumwald, "Engineering salt tolerance in plants," Current Opinion in Biotechnology, vol. 13, no. 2, pp. 146150, 2002.

[8] S. L. Singla-Pareek, M. K. Reddy, and S. K. Sopory, "Genetic engineering of the glyoxalase pathway in tobacco leads to enhanced salinity tolerance," Proceedings of the National Academy of Sciences of the United States of America, vol. 100, no. 25, pp. 14672-14677, 2003.

[9] M. F. Álvarez-Viveros, C. Inostroza-Blancheteau, T. Timmermann, M. González, and P. Arce-Johnson, "Overexpression of GlyI and GlyII genes in transgenic tomato (Solanum lycopersicum Mill.) plants confers salt tolerance by decreasing oxidative stress," Molecular Biology Reports, vol. 40, no. 4, pp. 3281-3290, 2013.

[10] M. Hasanuzzaman, M. M. Alam, A. Rahman, M. Hasanuzzaman, K. Nahar, and M. Fujita, "Exogenous proline and glycine betaine mediated upregulation of antioxidant defense and glyoxalase systems provides better protection against saltinduced oxidative stress in two rice (Oryza sativa L.) varieties," BioMed Research International, vol. 2014, Article ID 757219, 17 pages, 2014.

[11] S. H. Jin, X. Q. Li, G. G. Wang, and X. T. Zhu, "Brassinosteroids alleviate high-temperature injury in Ficus concinna seedlings via maintaining higher antioxidant defence and glyoxalase systems," AoB PLANTS, 2015.

[12] P. Cañon, F. Aquea, A. R.-H. de la Guardia, and P. Arce-Johnson, "Functional characterization of Citrus macrophylla BOR1 as a boron transporter," Physiologia Plantarum, vol. 149, no. 3, pp. 329-339, 2013.

[13] K. Carvalho, M. K. F. de Campos, L. F. P. Pereira, and L. G. E. Vieira, "Reference gene selection for real-time quantitative polymerase chain reaction normalization in 'Swingle' citrumelo under drought stress," Analytical Biochemistry, vol. 402, no. 2, pp. 197-199, 2010.

[14] S. L. Singla-Pareek, S. K. Yadav, A. Pareek, M. K. Reddy, and S. K. Sopory, "Enhancing salt tolerance in a crop plant by overexpression of glyoxalase II," Transgenic Research, vol. 17, no. 2, pp. 171-180, 2008.

[15] A. Ghosh, A. Pareek, S. K. Sopory, and S. L. Singla-Pareek, "A glutathione responsive rice glyoxalase II, OsGLYII-2, functions in salinity adaptation by maintaining better photosynthesis efficiency and anti-oxidant pool," The Plant Journal, vol. 80, no. 1, pp. 93-105, 2014.

[16] B. Rewald, E. Raveh, T. Gendler, J. E. Ephrath, and S. Rachmilevitch, "Phenotypic plasticity and water flux rates of Citrus root orders under salinity," Journal of Experimental Botany, vol. 63, no. 7, pp. 2717-2727, 2012.

[17] J. P. Syvertsen and F. Garcia-Sánchez, "Multiple abiotic stresses occurring with salinity stress in citrus," Environmental and Experimental Botany, vol. 103, pp. 128-137, 2014.

[18] S. Devanathan, A. Erban, R. Perez-Torres Jr., J. Kopka, and C. A. Makaroff, "Arabidopsis thaliana glyoxalase 2-1 is required during abiotic stress but is not essential under normal plant growth," PLoS ONE, vol. 9, no. 4, Article ID e95971, 2014.

[19] M. Choudhary, Jayanand, and J. C. Padaria, "Transcriptional profiling in pearl millet (Pennisetum glaucum L.R. Br. ) for identification of differentially expressed drought responsive genes," Physiology and Molecular Biology of Plants, vol. 21, no. 2, pp. 187-196, 2015. 

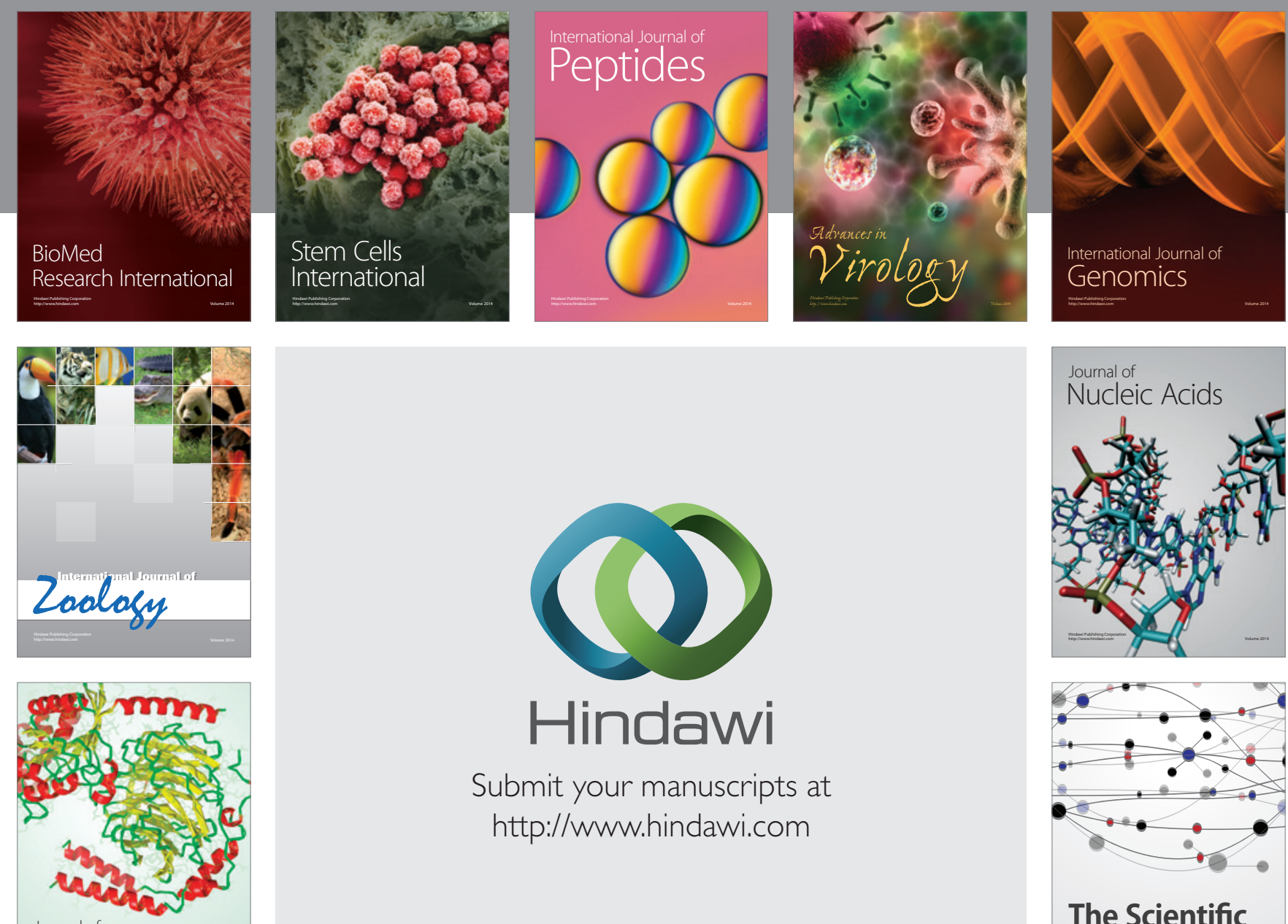

Submit your manuscripts at

http://www.hindawi.com

Journal of
Signal Transduction
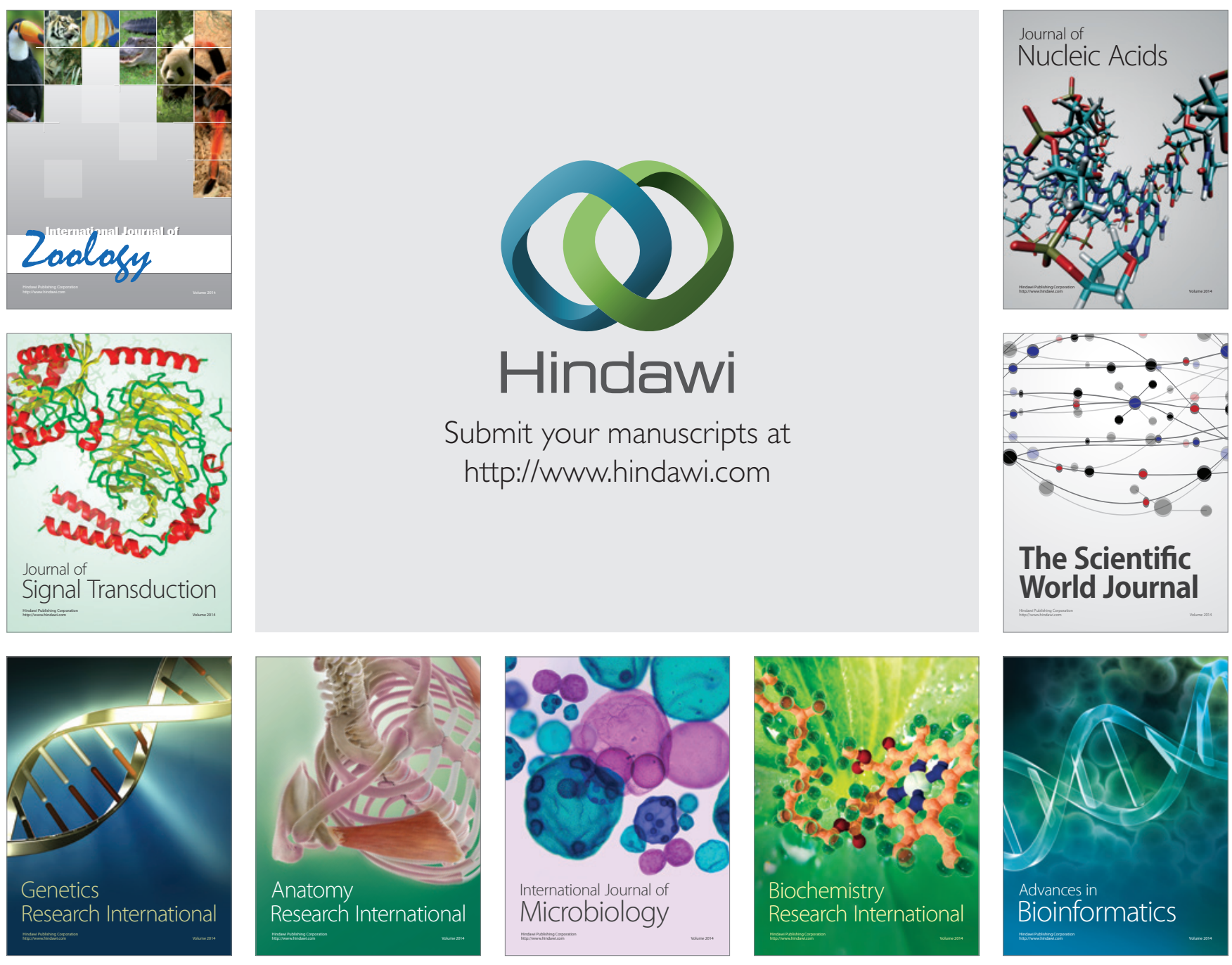

The Scientific World Journal
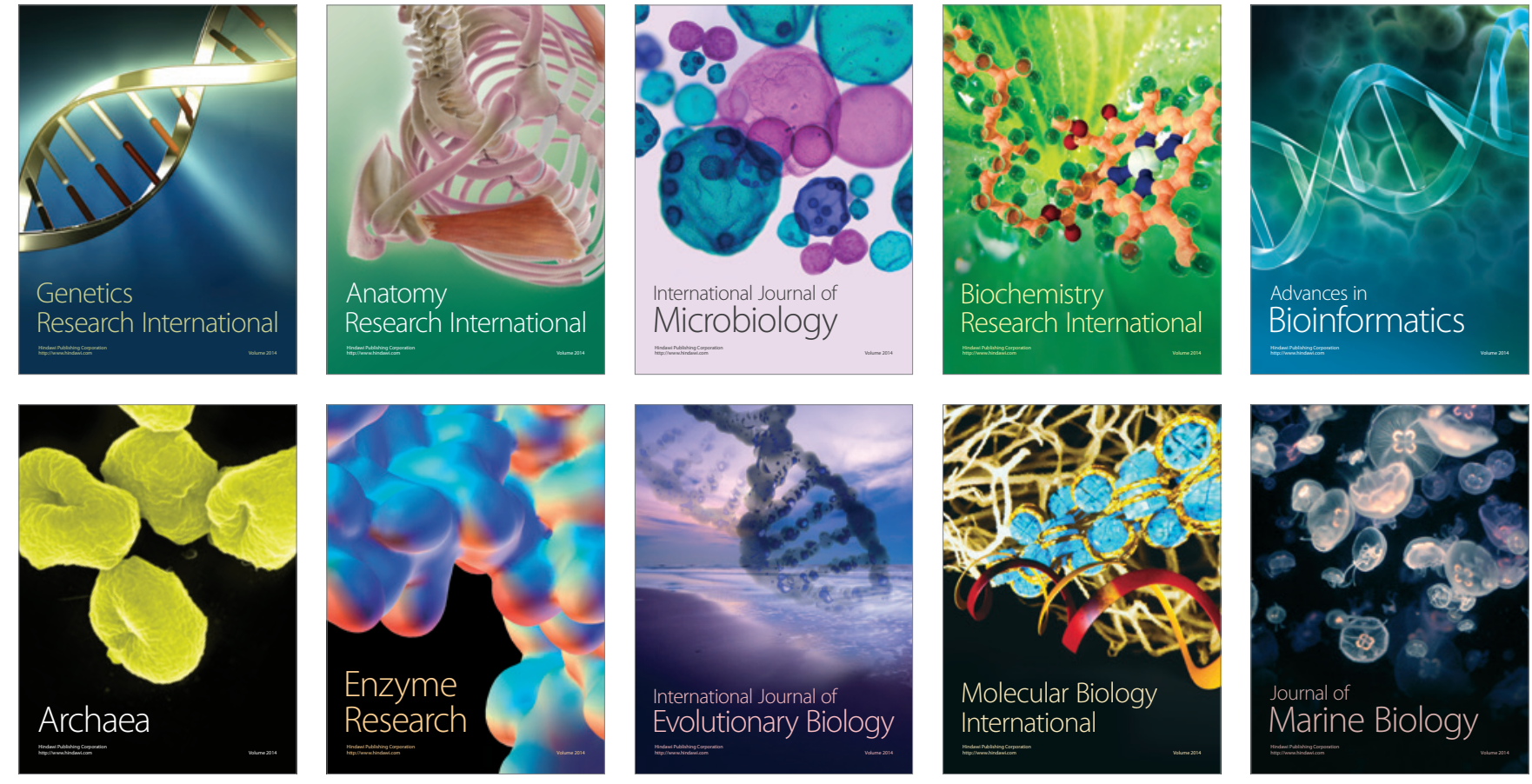